\title{
Task-Based Language Teaching: An Insight into Teacher Practice
}

\author{
Dao Thi Thanh Hao \\ International Education Centre, Hanoi University, Nguyen Trai, Thanh Xuan, Hanoi, Vietnam
}

Email address:

haodt@hanu.edu.vn, haodtt2014@gmail.com

\section{To cite this article:}

Dao Thi Thanh Hao. Task-Based Language Teaching: An Insight into Teacher Practice. International Journal of Education, Culture and Society. Vol. 2, No. 4, 2017, pp. 126-131. doi: 10.11648/j.ijecs.20170204.14

Received: December 26, 2016; Accepted: January 6, 2017; Published: September 30, 2017

\begin{abstract}
The current case study is an attempt to get an insight into a teacher's actual experiences of TBLT adoption at a Vietnamese University to delineate the bridge from TBLT theory to TBLT practice in Vietnamese context. Observation and semi -structured interview were employed to collect qualitative data. The findings from both instruments showed that the teacher practice did not really reflect the core tenets of TBLT approach since there existed several worth-concerning reasons behind her decision making in terms of group work culture, low-level students, and pressure from examination preparation.
\end{abstract}

Keywords: Task-Based Language Teaching, Teacher Practice, Vietnamese Context

\section{Introduction}

In the globalized context, English has become the golden key to the integration door that allows Vietnam to catch up with the socio-economic development in ASEAN region as well as the whole world. Vietnamese Ministry of Education and Training (MOET), therefore has implemented a number of projects and policies to foster the quality of EFL teaching and learning with the utmost goal that students can communicate well in English. Task-based language teaching (TBLT) deriving from communicative language teaching (CLT) method appears to be an effective approach for achieving this objective. This approach is motivated and drawn on the idea that learners best learn when they are actively involved in constructing their own knowledge through experiences and problem solving [1]. In this light, learners are supposed to acquire the target language by completing different tasks through meaningful communication. Many Vietnamese teachers of English have already applied TBLT in their own classrooms and obtained both expected and unexpected results. This is because there exist many factors hindering the efficacy of English teaching and learning and a considerable divergence between teacher beliefs and their actual practice. This inspired the author to conduct the current research to exploring the actual TBLT practices of a teacher and the challenges she really faced when implementing this approach in her own classroom.

\section{Literature Review}

\subsection{Notion of Tasks and TBLT}

Within a number of interpretations of TBLT related to classroom practice, four outstanding features of the approach are emphasized. First, TBLT is compatible with a learner-centered educational philosophy, which encourages minimal teacher input during the tasks [2-5]. Second, it comprises particular components such as goal or specific outcome in order to signify the successful completion of the task [5-7]. Third, it focuses on meanings rather than linguistic forms to promote natural communicative competence among learners [8-11]. Fourth, it enables learners to learn through communication and engagement $[12,13]$.

In TBLT, a task is viewed as a central unit of planning and teaching. Nunan [7] identified five essential characteristics of tasks: (1) meaning is primary; (2) there is some communication problem to solve; (3) there is some sort of relationship to comparable real-world activities; (4) task completion has some priority; and (5) the assessment of the task is in terms of outcome.

There have been different types of task classified by various educators and researchers. Due to the small scope of this paper, Willis and Willis [14]'s classification underpinned the decision making of the teacher participant in the current study. 
As to their literature, taxonomy of task types are described as detailed in the table below.

Table 1. Taxonomy of task types in Willis and Willis (2007).

\begin{tabular}{ll}
\hline Task types & Examples of specific tasks \\
\hline & Brainstorming \\
Listing & $\begin{array}{l}\text { Fact-finding } \\
\text { Games based on listing: quizzes, memory, and } \\
\text { guessing } \\
\text { Sequencing }\end{array}$ \\
& $\begin{array}{l}\text { Ranking ordering } \\
\text { Ordering and sorting }\end{array}$ \\
Comparing and & Game finding similarities and differences Graphic \\
contrasting & organiser \\
Problem solving tasks & Logic problem prediction \\
Projects and creative & Newspaper \\
tasks & Posters \\
& Survey fantasy \\
Sharing personal & Story telling \\
experience & Anecdote \\
Matching & Reminiscence \\
\hline
\end{tabular}

\subsection{TBLT in Asian Context}

In order to achieve the utmost goal of effectively communicating in English, Asian educators and governments over the past decades have shifted national policies and syllabuses towards various versions of communicative language teaching including TBLT $[15,16]$. However, many studies in different countries of the region have revealed a mismatch between the core features of TBLT and local practicing such as those in Hong Kong (Carless [17], Carless [18], Ruffell [19]), China (Yuan [20], Liu [21], Tong[22]; Yuying \& Tao [23]), Korea (Yoon[24], Jeon \& Hahn [25]), Japan (Nishino \& Wantanabe [26]; (Romanko, 2012 [27]), and Thailand (Nonkukhetkhong, Baldauf \& Moni [28]; Segovia \& Hardison [29], Tayjasanant \& Barnard [30]). For example, in Thailand, teachers own varying interpretations of CLT and TBLT, which were not congruous with what they practiced in their classrooms. Although teachers stated to use activities like information gap, brainstorming or problem solving, "grammar explanation, vocabulary explanation, translation and whole class drills and repetition" were commonly documented in their classes [28 p6-7]. In Hong Kong, a wide gap between learning intentions and practical realities was also captured due to the lack of teacher preparation and understanding about TBLT [19]. In China, since the government's policy of promoting CLT among the teaching community in 1992, there has been much criticism about the eventual adoption of the approach as "the high investment but low output" [31 p4]. This results from the large-scale non-communicative testing system, and a lack of qualified teachers in schools [32]. Consequently, the application of CLT in general and TBLT in specific has endorsed to be counterproductive and a mere"matter of paying lip-service" [23]. In Vietnam, a growing body of research on TBLT has also been recorded over the past decade including those of (Canh \& Barnard [33]; Phuong [34]; Barnard \& Nguyen [35]; Nguyen, Newton \& Crabbe [36]). To be more specific, Canh and Barnard [33] investigated the implementation of curricular innovation (consited TBLT practice) behind closed classroom doors in high school. Their findings indicated that there exists a wide gap between learning intention of innovation designers and what is actually done by teachers, which is due to the washback effects on examinations, insufficient learning resources, time pressure, and lack of motivation. In her case study, Phuong [34] well-documented the real experiences of a teacher teaching writing skill under TBLT adoption. Her findings showed that the teacher's struggle related to both lesson preparation and teaching time due to their familiarity of PPP. For the sake of brevity, this study contributes another voice to the growth of research conducted by Vietnamese scholars regarding the gap between intended reform and real-life versions that are actually done in the classrooms.

\section{The Study}

\subsection{Participant}

The participant in this case study was Cindy (pseudo name), a college teacher with eight-year- teaching experience. She usually taught General English with the focus on four main skills (speaking, listening, reading, and writing) for students of an offshore program in coordination with Hanoi University. Regarding speaking skill, every week, these students had two speaking lessons with Vietnamese teacher (Cindy), and one lesson with an English teacher; each lesson lasted for one and a half hour. There were 30 students at pre-intermediate level in her class. All students were required to achieve 5.5 IELTS to be eligible for the offshore program.

Cindy twice participated in training workshop on communicative language teaching methods and TBLT approach so she was voluntary to join this study to know whether what she learnt from the training courses was really reflected in her practices in her own classroom.

\subsection{Research Questions}

The current paper attempts to answer the following research questions:

(1) To what extent did Cindy implement TBLT practice in her actual classroom?

(2) What challenges did Cindy face when implementing TBLT practice?

\subsection{Data Collection and Procedures}

The data used in this paper were drawn from observation and semi-structured interview. Observation is frequently utilized by researchers to obtain comprehensive data in qualitative research especially when a composite of both oral and visual data become vital to the study. The teacher in this study was observed over three weeks (six lessons overall). Camera use was applied to capture the performance of both teacher and students. This would ensure that no important information was missing, which enabled the researcher to collect reliable findings. 
Semi-structured interviews have been used by a massive number of researchers to obtain qualitative data as interviews are aimed at accumulating the data that is not directly observed. After the last observed lesson, the teacher was asked to attend a semi-structured interview that lasted for about 20 to 25 minutes. The interview was conducted in Vietnamese so that the participant could easily express her views and opinions without being hindered by the use of a second language. All the arising important issues from observation related to teacher belief towards TBLT and challenges in the implementation of TBLT were asked. The interview was then transcribed, translated into English, and analyzed by the author to highlight outstanding themes.

\subsection{Findings}

\subsubsection{Observation Data}

Observation notes of Cindy's teaching revealed some gaps between her beliefs and her actual practices. These gaps are analyzed in accordance with four main features of TBLT that was aforementioned early somewhere in the paper.

$i$. TBLT is compatible with a learner-centered educational philosophy

Despite some endeavor to design tasks that encourage learner-centeredness, Cindy's classroom teaching remained teacher-led with much teacher intervention and demonstration. This is well illustrated in the extracts as detailed below.

Extract 1: (Topic "National festivals", comparing task)

Cindy: Now I want you to work in pairs using these pictures and cards. One will describe a picture but do not let your partner know what it is; another will listen and match the card of activity correspondingly to the picture. $\mathrm{H}$, can you come here so that we can demonstrate the task for the whole class to understand?

(Cindy and her student demonstrate the describing and matching task)

(The students work in pairs)

S: Excuse me, I do not know how to say "drop flower lanterns on the river" (asks in Vietnamese)

Cindy: Oh, that is "drop flower lanterns on the river" (answers in English)

Extract 2: (Topic "Daily routine", act-finding task)

Cindy: You are going to listen to a singer who talks about her daily routine. During your listening, please take note of any routine verbs that she mentions. Here are some phrases that you might not know: make an appointment, go to recording studio, and sign autographs. So try to recognize these words when the singer mentions them in the recording. (Cindy writes the verb phrases on the board)

Cindy: Well, "making appointment" means you arrange a meeting with someone in advance. Ok? So who can guess the meaning of this phrase in Vietnamese?

(Students ask each other, then some of them say some Vietnamese words that they think are the meaning of the phrase; Cindy confirms and students note down on their notebooks)

ii. TBLT comprises particular components such as goal or specific outcome
In every Cindy's lesson, she always set defined goals or outcomes for her students to achieve.

Extract 3: (Topic "Food", creative task)

Cindy: The last task of today lesson is that you work in groups of three, inventing a new food with special recipe. You should use dictionary to look up new words when doing the task. In the next 5 minutes, each group will have to present your food in front of the whole class.

Extract 4: (Topic "Food", problem-solving task)

Cindy: (gives handouts to each pair) Are you ready for the activity? Okay, now each pair will have 10 minutes to decide the seat arrangement in a restaurant for different customers with different requests. After 10 minutes, one of person in your team will present your report and of course explain the reasons for such decision. Do you get it?

iii. TBLT focuses on meanings rather than linguistic forms

In TBLT, the instructed language learning should primarily involve natural or naturalistic language use, based on activities concerned with meaning rather than language. As such, students may interact with each other or retrieve their existing knowledge to do the task without being interrupted to promote fluency and natural speaking [7]. What Cindy did in her classroom seemed not to reflect the literature aforementioned. She tried to correct mistakes the students had, lecturing about grammar, and using drills to support students. Following extract proves this clearly.

Extract 5: (Topic “Health", sharing personal experience task)

S: Smoking harmful to our health. It causes lung cancer, not good for body of smokers and body of other people. Smoking also makes pollution environment. In the smoke have a lot of bad chemicals so the air dirty because the smoke. Third, smoking waste of money. People have to pay many money to buy cigarettes and also the tax. For three reasons, we think smoking should ban in public.

(Teacher takes note on what student says)

Cindy: Very good. Please give him a big hand (claps her hands). But be careful with the grammatical mistakes related to verbs. Many of your sentences miss a verb. For example, you have to say "Smoking is harmful", "It is not good for health", "Smoking is a waste of money". You should pay attention to passive voice like "smoking should be banned". (goes to the board and writes while saying) A passive voice sentence is formed like this: Subject- Be- PP. Ok, now can you make a passive voice sentence following this form? ....

iv. TBLT enables learners to learn through communication and engagement

Cindy attempted to design various tasks to encourage students' communication and cooperation by asking them to work in pairs and in groups. However, she encountered difficulties in putting them in mixed-ability groups since the students seemed to be interested in working with their close friends, and felt reluctant to join the group of unfamiliar people. Hence, most of the time Cindy let students freely form groups themselves. This led to the fact that some weak students who worked in one group hardly learnt anything from each other, while students in strong group finished the task 
earlier and started to chat or do off-tasks. The phenomenon can be illustrated vividly through some extracts as follows.

Extract 6:

S1: Teacher, two of us want to work together. Can you put us in one pair, please?

Cindy: Okay, so you can move to sit next to her if you want (sighs)

S2: Teacher, I am interested in working with her (points to her friend), please let me work with her (talks in Vietnamese).

Cindy: All right. Now let's start your work, class (claps her hands to urge the class to stay focus on their task)

(When the time for the task is up, Cindy asks each pair to present their report)

S3: I am sorry, teacher. Both of us do not know many new words so we have very little to say (talks in Vietnamese)

\subsubsection{Interview Data}

After the last lesson, an interview was implemented to explore the rationales for her practice and the challenges she faced during TBLT adoption. Three important issues were highlighted from her responses to the researcher.

\section{i. Low-level students}

Cindy revealed the reason behind her use of Vietnamese language and translation in her classroom practice was her students' low-level English proficiency. In Cindy's class, most of students were at pre-intermediate level, some of them were even at elementary level. Although they had formal English education at school for at least seven years, the traditional ways of teaching and learning English in their school played the most emphasis on teaching grammar. Therefore, the students' English proficiency primarily limited in grammar knowledge. The following quotes illustrate such obstacle.

I had to translate words into Vietnamese; otherwise, most of my students could not understand and thus could not acquire much knowledge from the lesson.

When I asked and my students just smiled without saying anything, at that time I knew that they were unable to understand what I meant. What else should I do but using their mother tongue?

I understood that I should not provide much input for the students when applying TBLT, but without my frequent support, they could not finish the tasks because you know, their English was limited.

ii. Exam pressure

The students in this study had to take the IELTS examination included four main skills (listening, reading, writing, and speaking). In the speaking test, the examinees are required to talk about a topic given and show their communicative competence by answering some follow-up questions. Therefore, TBLT approach seemed to be a perfect fit for their exam preparation. However, the problem Cindy frankly stated as follows raised some concerns in her actual practice of TBLT.

I agree that my practice was sometimes grammar-focused and teacher-controlled in terms of analyzing the grammatical structures and frequently correcting mistakes for my students. However, I needed to ensure that my students really understood the vocabulary and structures and avoided mistakes in their real test. If I did not show them carefully, they would by no way recognize such things.

I think it was necessary to provide students with some templates or common expressions to be used in the speaking test so that they could earn high score. 5.5 IELTS is their important goal.

\section{iii. Team Work Culture}

Most of time, Cindy let her students freely choose partners when they were required to perform teamwork. This resulted in the fact that sometimes there were all weak students or all strong students in one group. She explained for her easy-going mind as this:

The students often feel reluctant to work in a group or a pair that they were not familiar. So they tend not to get involved in the tasks. That is Vietnamese's team work culture, you know. I just wanted them to have comfortable feeling to effectively implement the tasks so I let them choose the partners themselves.

\subsection{Discussion}

The findings from Cindy's story indicate the lack of congruence between the core features of TBLT and actual practice of the teacher, which are consistent with the findings of other studies conducted in Asian context mentioned in early literature.

On the tip of the iceberg, Cindy was somehow successful in terms of following two main ethos of TBLT, i.e. promoting students 'communication as well as collaborative learning, and setting the defined outcomes for them to reach. She encouraged pair work and group work among students, and set a finishing line as a learning motivation for them to complete the tasks. However, when deeply digging into the first issue, Cindy's intention of putting students into pairs or groups failed since they were not willing to work with someone whose strengths or weaknesses they did not know. The phenomenon was in line with the finding of Nguyen [37] in that Vietnamese students had a strong desire to work with friends they were allowed to select rather than with ones the teacher randomly assigned to their group. As regard the second issue, Cindy's students seemed to rush through the tasks without using much of target language spoken. They appeared much similar to what Seedhouse described in that the student were "so concentrated on completing the task that linguistic forms are treated as a vehicle of minor importance" [38 p154]. Consequently, "the pedagogical and interactional focus is on the accomplishment of the task rather than on the language use" [38 p50]. This likely resulted in the learners' inaccurate target language, or pidgin language, which hampered their communicative competence development.

On the other hand, Cindy's TBLT implementation was unsuccessful regarding the issues of student-centered philosophy and the emphasis on meaning rather than forms. This is due to her suffering from examination pressure and the students' low-level of English proficiency. For these two factors, Cindy's lessons tended to be teacher-led with considerable grammar translation, vocabulary translation, 
mother-tongue use, drills and correction. She explained that she needed to ensure everyone in her class acquired the knowledge necessary for their exam preparation. Obviously, Cindy could show her students their mistakes at the end of the task but once she repeated her interference many more times, the classroom turned into a controlled environment, which minimised the natural target language being spoken, and thus, diminished the real world nature of the experience for her students. She also could explain vocabulary meanings but should do this by developing individual thinking process or the negotiation meaning among the students rather than using translation and drills.

\section{Conclusion}

In conclusion, the current study seeks to explore the gap between TBLT theory and teachers 'actual TBLT practice in Vietnamese tertiary context. It significantly contributes to the understanding of the factors and reasons behind teacher decisions in a non-English speaking country where students lack opportunities to practice their English outside the classroom. The results suggest notable concerns related to culture (group work/pair work), English proficiency, and wash-back effects of examination. As Kember and Gow [39] state, learning cannot be simple borrowed and implemented in all contexts. Rather, it is influenced and formed by various factors consisting teaching methods, learning tasks, assessment demands, workload and culture of students. Therefore, Asian educators should not assume that "what has been done successfully in the West will produce the similar outcomes in the East" [ 40 p521]. Although the findings of this study herein may not be well generalized to other cases, it is implicated from the story of Cindy that different stakeholders need to commit themselves to the educational plenary changes in Vietnam. Otherwise, CLT innovation like TBLT is just a "paying lip-service", which unnecessarily brings fruitful outcomes for Vietnamese EFL learners in their long-life learning path.

\section{References}

[1] Larsen-Freeman, D., \& Anderson, M. (2011). Techniques and principles in language teaching. Oxford: Oxford University Press.

[2] Ellis, R. (2003). Task-based language learning and teaching. USA: Oxford University Press.

[3] Nunan, D. (2005). Important tasks of English education: Asia-wide and beyond. Asian EFL Journal, 7 (3).

[4] Richards, J. C., \& Rodgers, T. S. (2001). Approaches and methods in language teaching (2nd ed). Cambridge: Cambridge University Press.

[5] Skehan, P. (1996). A framework for the implementation of task-based instruction. Applied Linguistics, 17, 38-62.

[6] Murphy, J. (2003). Task-based learning: The interaction between tasks and learners. ELT Journal, 57 (4), 352-360.
[7] Nunan, D. (2004). Task-based language teaching. Cambridge, England: Cambridge University Press.

[8] Skehan, P. (1996). A framework for implementation of task-based instruction. Applied Linguistics, 17, 38-62.

[9] Beglar, D. \& Hunt, A. (2002). Implementing task-based language teaching. In: Richards, J. C. \& Renandya, W. A. (Eds.). Methodology in language teaching: An anthology of current practice. Cambridge: Cambridge University Press.

[10] Carless, D. (2002). Implementing task-based learning with young learners. ELT Journal, 56, 389-396.

[11] Littlewood, W. (2004). The task-based approach: some questions and suggestions. ELT Journal, 58, 319-326.

[12] Prabhu, N. (1987). Second language pedagogy: A perspective. Oxford: Oxford University Press.

[13] Skehan, P. (1998a). Task-based instruction. Annual Review of Applied Linguistics, 18, 268-286.

[14] Willis, D., \& Willis, J. (2007). Doing task-based teaching. Oxford: Oxford University Press.

[15] Adams, R. \& Newton, J. (2009). TBLT in Asia: Constraints and opportunities. Asian Journal of Englsih Langue Teaching, 19, $1-17$.

[16] Nunan, D. (2003). The impact of English as a global language on educational policies and practices in the Asia-Pacific region. TESOL Quarterly, 37 (4), 589-613.

[17] Carless, D. (2012). TBLT in EFL settings: Looking back and moving forward. Task-based language teaching in foreign language contexts: Research and implementation, 345-358.

[18] Carless, D. (2007). The suitability of task-based approaches for secondary schools: Perspectives from Hong Kong. System, 35 (4), 595-608.

[19] Ruffell, Y. L. (2006). Curriculum intentions versus realitites in English language education: A Hong Kong study. Retrieved November 5, 2016 from http://k1.ioe.ac.uk/May2006/Paers/LinRuffell_Paper.doc.

[20] Yuan, Y. (2016). Application of Task-based Learning in Chinese Context. Theory and Practice in Language Studies, 6 (2), 392 .

[21] Liu, W. (2016). The changing pedagogical discourses in China: the case of the foreign language curriculum change and its controversies. English Teaching: Practice \& Critique, 15 (1).

[22] Tong, S. (2005). Task-based learning in English in English language in Hong Kong secondary schools. HKU Theses Online (HKUTO).

[23] Liu, Y., \& Xiong, T. (2016). Situated Task-based Language Teaching in Chinese Colleges: Teacher Education. English Language Teaching, 9 (5), 22.

[24] Yoon, K. (2004). CLT theories and practices in EFL curricula: A case study of Korea. The Asia EFL Journal, 6 (3).

[25] Jeon, I. J., \& Hahn, J. (2006). Exploring EFLT teachers' perceptions of task-based language teaching: A case study of a Korean secondary school classroom practice. The Asian EFL Journal Quarterly, 8 (1), 123. 
[26] Nishino, T., \& Watanabe, M. (2008). Communication-oriented policies versus classroom realities in Japan. TESOL Quarterly, 42 (1), 133-138.

[27] Romanko, R., \& Nakatsugawa, M. (2010). Task sequencing based on the Cognition Hypothesis. In A. M. Stoke (Ed.), JALT2009 Conference Proceedings. Tokyo: JALT.

[28] Nonkukhetkhong, K., Baldauf Jr, R., \& Moni, K. (2006). Learner-centeredness in teaching English as a foreign language: Teachers' voices. Paper presented at 2006 Thai TESOL International Conference, Chiang Mai, Thailand.

[29] Segovia, L. P. D., \& Hardison, D. (2009). Implementing education reform: EFL teachers' perspectives. ELT Journal, 63 (2), 154-162.

[30] Tayjasanant, C., \& Barnard, R. (2010). Language teachers' beliefs and practices regarding the appropriateness of communicative methodology: A case study from Thailand. Journal of Asia TEFL, 7 (2), 277-311.

[31] Chen, X. H., Jiang, P., \& LU, J. W. (2004). Yingyu xuexi wenti (Problems in learning English). Wenhui Daily, 4.

[32] Yu, L. (2001). Communicative Language Teaching in China: Progress and Resistance. TESOL Quarterly, 35 (1), 194-198.

[33] Canh, L. V., \& Barnard, R. (2009). Curricular innovation behind closed classroom doors: A Vietnamese case study. Prospect, 24 (2), 20-33.
[34] Phuong, H. Y. (2016). Challenges of shifting to task-based language teaching: A story from a Vietnamese teacher. Can Tho University Journal of Science, 2, 37-45.

[35] Barnard, R., \& Nguyen, G. V. (2010). Task-based language teaching (TBLT): A Vietnamese case study using narrative frames to elicit teachers' beliefs. Language Education in Asia, 1 (1), 77-86.

[36] Nguyen, B. T., Newton, J., \& Crabbe, D. (2015). Preparing for tasks in Vietnamese EFL high school classrooms: Teachers in action. In M. Thomas \& H. Reinders (Eds.) TBLT in Asia: Challenges and Opportunities, pp. 170-188. London: Bloomsbury.

[37] Nguyen, P. M. (2008). Culture and cooperation cooperative learning in Asian Confucian heritage cultures: The case of Viet Nam. Netherlands: IVLOS Institute of Education of Utrecht University.

[38] Seedhouse, P. (1999). Task-based interaction. ELT Journal, 53, 149-156.

[39] Kember, D., \& Gow, L. (1994). Orientations to teaching and their effect on the quality of student learning. Journal of Higher Education, 65 (2), 58-74.

[40] Thanh Pham Thi Hong. (2011). Issues to consider when implementing student-centered learning practices at Asian higher education institutions. Journal of Higher Education Policy and Management, 33 (5), 519-528. 